\title{
Management and Prevention of Burnout in the Dental Practitioner
}

\section{Basson RA*}

Oral and Dental Research Institute, Faculty of Dentistry, University of the Western Cape, Private Bag X1, Tygerberg 7505, Cape Town, South Africa

\begin{abstract}
The aim of this article is to review the available literature to provide the clinician with information to recognize the onset of burnout, the psychological and physiological effect, the effect on the dentist-patient interaction and the provision of practical methods to address the problem. Emotional exhaustion, depersonalisation and diminished personal accomplishment comprise the three dimensions of burnout which affect the well-being of both the dentist and the patient-dentist relationship. Engagement is the direct opposite of burnout. The three dimensions of engagement, namely, energy, involvement and efficacy may be viewed as the opposites of the three dimensions of burnout. Burnout is the result of chronic interpersonal work related stressors. The high incidence of burnout among dentists can be ascribed to the interpersonal context of the occupation. Various interacting psychosocial factors are involved in the aetiology of burnout in dentists, namely, work related stressors, dentist-patient interaction, perception of stress and the personality traits of the clinician. It is clear how detrimental burnout is to the dentist-patient relationship and that the maintenance of a stance of engagement is of paramount importance. In addition to maintaining the well-being of the clinician, dental health service delivery can therefore be improved by early recognition and treatment of burnout.
\end{abstract}

Keywords: Mindfulness; Burnout; Prevention; Dentist; Stress

\section{Introduction}

While the restoration of oral health and maintenance of the patient's well-being is of prime importance in the dental profession, the well-being of the service-provider should not be neglected. According to Maslach et al. [1] the experience of burnout comprises three core dimensions. The aim of this article is to review the available literature to provide the clinician with information to recognize the onset of burnout, the psychological and physiological effect, the effect on the dentist-patient interaction and the provision of practical methods to address the problem.

\section{Definition of Burnout}

Burnout is the result of chronic interpersonal work related stressors. Emotional exhaustion (stress dimension), depersonalisation (interpersonal dimension) and diminished personal accomplishment (self-evaluation dimension) comprise the three dimensions of burnout which could lead to depression, reduced work performance and fatigue [2]. A study by Ahola and Hakanen [3] found a reciprocal relationship between burnout and depressive symptoms. Depersonalisation can be considered a self-protection mechanism against emotional exhaustion, resulting in a negative and cynical attitude toward the patient as well as an attitude of detachment. Chronic exhaustion with consequent emotional and cognitive distancing leads to a perception of inefficacy $[1,4]$. According to Burke and Richardson [5] burnout often develops into a chronic condition, thus posing a significant threat to good dental care $[6,7]$.

\section{Incidence of Burnout among Dentists}

Several studies have reported a high prevalence of burnout among dentists [7-10]. This can be largely ascribed to the interpersonal context of the job. As health care provider the dentist is subject to interpersonal stressors due to the demanding nature of the occupation and close proximity to the patient. Work-stress and long working hours may have a negative effect on the dentist's psychological well-being and family life [11]. Peterson et al. [12] study on service workers (including dentists) showed an association between burnout and depression, anxiety, alcohol consumption, sleep and memory problems as well as musculoskeletal complaints.

\section{Stress Inducing Factors}

The following factors were considered to contribute to burnout in dentistry:

\section{Work-related stressors}

Workload [1]: A high patient load and time pressure leads to exhaustion, the stress dimension of burnout.

Lack of sufficient control [1]: Insufficient control over resources for effective service provision could be a factor in community-based dentistry.

Lack of recognition and appropriate reward [1]: The skill and quality of workmanship provided by the dentist is often not appreciated by the patient because it is often not visible, e.g. in the case of a rootcanal procedure or restorations in the anterior of the oral cavity. Feelings of inefficacy may result due to lack of reward [7].

Lack of social support: According to the "buffering hypothesis" the interaction between job stress and burnout is moderated by social support [1].

Quality of working life: This factor was primary in the prediction of stress [13]. Felton [7] also noted that problems involving the physical environment and poor working posture contributed significantly to burnout.

Occupational hazards: Exposure to the human immune deficiency virus (HIV), tuberculosis (TB) and the hepatitis B virus (HBV) could also be considered as a stressor. Additional hazards are ocular problems (noise of hand pieces, etc.); eye injuries (blood-borne pathogens,

*Corresponding author: Basson RA, BA Psy, Hons Psy, MA Research Psy, Ora and Dental Research Institute, Faculty of Dentistry, University of the Western Cape, Private Bag X1, Tygerberg 7505, Cape Town, South Africa, Tel: +27 937 3024; Fax: +27 937 3025; E-mail: rbasson@uwc.ac.za

Received October 22, 2013; Accepted November 05, 2013; Published November 07, 2013

Citation: Basson RA (2013) Management and Prevention of Burnout in the Denta Practitioner. Dentistry 3: 168. doi:10.4172/2161-1122.1000168

Copyright: (c) 2013 Basson RA. This is an open-access article distributed under the terms of the Creative Commons Attribution License, which permits unrestricted use, distribution, and reproduction in any medium, provided the original author and source are credited. 
aerosols, mercury exposure, curing lights, etc.); latex allergy (gloves); and musculoskeletal pain (due to strained posture during dentistry procedures) [14].

\section{Dentist-Patient Interaction}

The stress resulting from the relationship between the dentist as helper and patient as recipient is an important factor in the development of burnout [7]. According to Leiter and Schaufeli [15] burnout presents in professions characterised by intense and direct contact with others. In their review on the effectiveness of different intervention programs in reducing burnout, Awa et al. [16] found that $82 \%$ of person-directed interventions resulted in a significant reduction in burnout for a period of approximately 6 months after completion. The interpersonal nature of the occupation is thus the focus in understanding burnout [1].

Attention-seeking behaviour, burdening the dentist with personal problems, manipulative behaviour, somatization, non-compliance, chronic pain, etc. are examples of patient-interaction which could be stressful to the dentist [4]. The source of fear and anxiety in adult dental patients often stems from negative encounters with a dentist in childhood. The dental equipment, noise and fear of injury may evoke anxiety [7]. In children anxiety may also be due to the role of parental modelling of fear of dental procedures [17]. The dentist needs to examine why he/she perceives the patient as difficult, change his/ her incorrect perception of the situation and acquire effective coping strategies in order to reduce the stress of the patient-dentist interaction.

Acknowledgement of the angry patient's feelings and concerns and providing sufficient information about treatment could reduce anxiety, empower the patient and reduce feelings of anger. Likewise, the demanding patient could also be concealing anxiety. The difficult patient (angry, demanding, non-compliant, anxious, addicted, chronic pain) may also reflect a degree of psychopathology. An awareness of this possibility and the realisation that the patient's reactions are determined by his/her perception of the situation may enable the dentist to avoid taking the patient's reactions too personally. Improved compliance can be attained by improving the dentist's listening and communication skills [4].

The BATHE technique to reduce stress when dealing with the angry patient involves the following [18]:

- Assess the background (B) of the problem. What is the patient experiencing today?

- Try to understand the affect (A) (emotion) evoked by the problem.

- Focus on what specifically troubles (T) the patient to determine the patient's perception of the problem.

- Note how the patient is handling $(\mathrm{H})$ the problem.

- Show empathy (E) and acknowledge feelings.

These steps enable the dentist to convey understanding of the patient's problem and reduce stress.

Additional steps for the management of difficult patients include the following [4]:

- Try to recognize negative emotional reactions in yourself (dentist).

- Identify what is difficult about an interaction with the patient.

- Clarify role expectations between dentist and patient.
- Collaborate with the patient to enhance compliance.

- Effective communication skills, empathic consideration of the patient's viewpoint, acknowledgement of the patient's feelings.

- Maintenance of dentist-patient boundaries.

\section{Personality Traits of the Clinician}

Persons with a higher risk for experiencing burnout portray the following personality traits, namely: low levels of hardiness; low selfesteem; external locus of control; a passive, avoidant or defensive coping style; neuroticism; type A behaviour; feeling type [1] and perfectionism [13]. According to Denollet [19] individuals with a type D personality are very susceptible to stress. The Type D Scale-14 (DS14) (distressed type) is a brief, reliable, measure of 2 dominant traits, namely, negative affectivity and social inhibition (SI). Persons who rate high on SI cope with negative emotions through conscious suppression of emotions accompanied by high interpersonal distress. Knowledge of one's status on this scale could assist in the management of stress [20]. The manner in which they cope with stressors is thus important in the aetiology of burnout. A study by Polman et al. [21] found that Type D individuals were associated with higher levels of perceived stress and increased levels of burnout.

\section{Perception of Stress}

The sources of stress are varied, but the important factor is the individual's perception and reaction to the stressor. Altering one's perception of a stressor and improving one's coping skills results in reduced stress experienced in terms of psychological and physiological reactions. The source of a stressor may be internal or external frustrations, conflicting needs or goals (causing cognitive dissonance) and pressures (to achieve goals; work-demands). Identification of the source could enhance coping with the stressor [4]. A study by Divaris et al. [10] noted a positive correlation between perceived stress and burnout in postgraduate dental students. A useful tool for measuring the perception of stress is the Perceived Stress Scale (PSS) [22]. According to Moore and Brødsgaard [23] dentists perceive the following as intense stressors: keeping to schedule; causing pain; work load too heavy; late and anxious patients. Hendrix's Stress in Dentistry Model [24] indicates that contributing stress factors like personal characteristics of the dentist, work factors and external factors, have psychological and behavioural consequences. Moore and Brødsgaard [23] shows how dentists' perceived stress and perception of the anxious patient may be related.

\section{Prevention of Burnout in the Dentist}

The recognition of burnout is important for prevention. A significant reduction in burnout by means of person-directed interventions (lasting up to 6 months) and organization-directed intervention (up to 1 year) was observed [16]. According to Maslach et al. [1] burnout can be most effectively addressed using a combination of individual and organizational interventions with engagement as a positive goal for intervention.

Various studies have been conducted to determine the efficacy of prevention programs in health care workers. Gorter et al. [25] recorded a reduction in symptoms of burnout in dentists after participation in a prevention program aimed at the restoration of personal balance by gaining insight into one's situation and formulating a personal plan of action. Salyers et al. [26] reported a significant decrease in emotional exhaustion and depersonalization in mental health professionals, following a one-day workshop to reduce burnout, namely, BREATHES 
(Burn-out Reduction: Enhanced Awareness, Tools, Hand-outs, and Education).

The Burnout Self-check provides an informal report while the Maslach Burnout Inventory (MBI) is widely used by researchers [1]. According to Gorter et al. [25] the recognition of burnout by means of feedback or a self-check questionnaire could be important for prevention. The prevention of burnout should also be viewed as a continuous process. According to Morse et al. [27], prevention should focus on the development of positive qualities, e.g. role-fulfilment and a sense of meaning and gratitude in addition to stress management.

\section{The following person-directed interventions may be effective for prevention of burnout}

Stress management: Stress management should be structured and focused on the individual needs of the practitioner with regards to incorporation of personality traits, results of the Maslach Burnout Inventory and the Perceived Stress Scale. Allostatic load, the long-term consequences of stress, eventually undermines immune system and memory functioning [4].

Cognitive-behavioural training: The maintenance of a positive stance leads to work-related hope and engagement. According to Schaufeli and Bakker [28], work engagement is a multidimensional affective-cognitive measure of well-being characterized by vigour, dedication and absorption. The development of role fulfilment, a sense of gratitude and meaning are considered important [27].

Mindfulness-Based-Stress-Reduction (MBSR): Significant improvement in burnout scores for the Emotional exhaustion, Depersonalization and Personal Accomplishment scales on the Maslach Burnout Inventory was recorded for health care workers after a course in MBSR (developed by J Kabat-Zinn in 1979) which was completed in 8 weeks (2.5 hours per week) with a 7-hour retreat [29].

Mindfulness meditation (MM) and Rapid relaxation (RR): Lovas et al. [30] proposed the incorporation of mindfulness practices in the dentistry curriculum in order to enhance professionalism, stress management and self-care. Mindfulness meditation fosters attentiveness, active listening, empathy, equanimity, presence, patience and acceptance. These qualities are important for the dentist-patient relationship. The rapid relaxation technique helps the dental student to manage anxiety in the self and in the patient. Quality of life can thus be improved for the clinician and the patient. In the current multicultural student population, mindfulness practices could be a unifying basis for the promotion of professionalism and self-care.

Recognition of daily stressors: A stress response may be physical, behavioural, emotional, or cognitive [31].

Narrative counselling: By means of a narrative approach [32], the dentist can be assisted to gain insight into his interpretation of the situation as emotionally stressful and be empowered to become an agent of change in his own life story. This empowerment is engendered through the realisation of one's strengths, coping skills and personal attributes in the narrative process. A clear perspective on goals or the re-setting of goals in terms of a more effective family-work balance can also be achieved.

Technology: Technological tools could enable clinicians to determine their level of burnout and electronically access burnout intervention strategies [27]. Feedback and self-check instruments may assist in burnout prevention [25].

Additional preventive factors are social and peer support, assertiveness training, physical exercise, progressive muscle relaxation (PMR), positive imagery and yoga. According to Morse et al. [27], the use of multiple prevention strategies may be advisable instead of relying on one technique.

\section{Conclusion}

According to Maslach et al. [1] engagement is the direct opposite of burnout. The three dimensions of engagement, namely, energy, involvement and efficacy may be viewed as the opposites of emotional exhaustion, depersonalisation and diminished personal accomplishment (the three dimensions of burnout). It is clear how detrimental burnout is to the dentist-patient relationship and that the maintenance of a stance of engagement is of paramount importance. In addition to maintaining the well-being of the clinician, dental health service delivery can therefore be improved by early recognition and treatment of burnout.

\section{References}

1. Maslach C, Schaufeli WB, Leiter MP (2001) Job burnout. Annu Rev Psycho 52: $397-422$

2. Maslach C, Jackson SE, Leiter MP (1996) Maslach burnout inventory manual. (3rdedn), Palo Alto, CA: Consulting Psychologists Press.

3. Ahola K, Hakanen J (2007) Job strain, burnout and depressive symptoms: A prospective study among dentists. J Affect Disord 104: 103-10.

4. Bodner S (2008) Stress management in the difficult patient encounter. Dent Clin N Am 52: 579-603.

5. Burke RJ, Richardsen AM (1992) Psychological burnout in organizations. New York: Marcel Dekker.

6. Murtomaa H, Haavio-Mannila E, Kandolin I (1990) Burnout and its causes in Finnish dentists. J Affect Disord 18: 208-212.

7. Felton JS (1998) Burnout as a clinical entity - its importance in health care workers. Occup Med 48: 237-50.

8. Osborne D, Croucher R (1994) Levels of burnout in general dental practitioners in the south-east of England. Brit Dent J 177: 372-377.

9. Gorter RC, Freeman F (2011) Burnout and engagement in relation with job demands and resources among dental staff in Northern Ireland. J Affect Disord 39: 87-95.

10. Divaris K, Polychronopoulou A, Taoufik K, Katsaros C, Eliades T (2012) Stress and burnout in postgraduate dental education. Eur $\mathrm{J}$ dent Educ 16: 35-42.

11. Pūrienè A, Aleksejūnienè J, Petrauskienè J, Balčiūnienè I, Janulytè V (2011) Occupational effects on the family well-being of dentists in Lithuania: A survey of dentists. Medicina (Kaunas) 47: 399-404

12. Peterson U, Demerouti E, Bergström G, Samuelsson M, Assberg M, et al. (2008) Burnout and physical and mental health among Swedish healthcare workers. J Adv Nurs 62: 84-95.

13. Coster EA, Carstens IL, Harris AMP (1987) Patterns of stress among dentists. J Dent Assoc S Afr 42: 389-394.

14. Ayatollahi J, Ayatollahi F, Ardekani AM, Bahrololoomi R, Ayatollahi A, et al (2012) Occupational hazards to dental staff. Dent Res J 9: 2-7.

15. Leiter MP, Schaufeli WB (1996) Consistency of the burnout construct across occupations. Anxiety, Stress Coping 9: 229-243.

16. Awa WL, Plaumann M, Walter U (2010) Burnout prevention: A review of intervention programs. Patient Educ Couns 78: 184-190.

17. Porritt J, Marshman Z, Rodd HD (2012) Understanding children's dental anxiety and psychological approaches to its reduction. Int J Paediatr Dent 22: 397-405.

18. Mc Culloch J, Ramesar S, Peterson H (1998) Psychotherapy in primary care the BATHE technique. Am Fam Physician 57: 2131-2134.

19. Denollet J (2005) DS14: Standard assessment of negative affectivity, social inhibition, and TYPE D personality. Psychosom Med 67: 89-97.

20. Denollet J (2000) Type D personality. A potential risk factor defined. J Psychosom Res 49: 255-266. 
21. Polman R, Borkoles E, Nicholls AR (2010) Type D personality, stress, and symptoms of burnout: The influence of avoidance coping and social support. $\mathrm{Br}$ J Health Psychol 15: 681-696.

22. Cohen S, Kamarck T, Mermelstein R (1983) A global measure of perceived stress. J Health Soc Behav 24: 386-396.

23. Moore R, Brødsgaard I (2001) Dentists' perceived stress and its relation to perceptions about anxious patients. Community Dent Oral Epidemiol 29: 73-80.

24. Hendrix WH (1986) Dental stress model and assessment questionnaire. Dent Clin North Am 3: S1-10.

25. Gorter RC, Eijkman MA, Hoogstraten J (2001) A career counseling program for dentistry: effects on burnout. Patient Educ Couns 43: 23-30.

26. Salyers MP, Hudson C, Morse G, Rollins AL, Monroe-DeVita M, et al. (2011) BREATHE: A pilot study of a One-day Retreat to reduce burnout among mental health professionals. Psychiatr Serv 62: 214-217.
27. Morse G, Salyers MP, Rollins AL, Monroe-De Vita M, Pfahler C (2012) Burnout in mental health services: A review of the problem and its remediation. Adm Policy Ment Health 39: 341-352.

28. Schaufeli WB, Bakker AB (2004) Job demands, job resources, and their relationship with burnout and engagement: a multi-sample study. J Organiz Behav 25: 293-315.

29. Goodman MJ, Schorling JB (2012) A mindfulness course decreases burnout and improves well-being among healthcare providers. Int J Psychiatry Med 43: 119-128.

30. Lovas JG, Lovas DA, Lovas PM (2008) Mindfulness and professionalism in dentistry. J Dent Educ 72: 998-1009.

31. Benson H, Stuart EM (1993) The wellness book. Birch lane Press, New York.

32. White M, Epston D (1990) Narrative Means to Therapeutic Ends. Dulwich Centre, Adelaide. 